\title{
Deformation and failure of carbon fiber composite specimens with embedded defects during tension-torsion test
}

\author{
Valery E. Wildemann, Tatyana V. Tretyakova, Elena M. Strungar, Mikhail P. Tretyakov \\ Center of Experimental Mechanics, Perm National Research Polytechnic University, Russia \\ wildemann@pstu.ru, bttp:/ /orcid.org/0000-0002-6240-4022 \\ cem.tretyakova@gmail.com, bttp:/ /orcid.org/0000-0001-9445-5185 \\ cem.spaskova@mail.ru,bttp://orcid.org/0000-0002-2246-8638 \\ cem_tretyakov@mail.ru,bttp://orcid.org/0000-0001-6146-6769
}

ABSTRACT. A need to timely reveal operational damages and technological defects requires a prompt control of states of structures made from composite materials and their consequent repairs aimed at service life extension. This work is devoted to the experimental study of inelastic deformation and fracture of specimens made from layer composite materials with prior introduced technological defects related to a possible inappropriate compacting and inappropriate bonding of material layers at a given restricted domain. The analysis is carried on the evolution of inhomogeneous deformation fields on the surface of carbon plastic specimens with an internal "delamination-type" defect under complex stress state. The method of active infrared thermography was used to identify the location and parameters of defects configurations. The obtained experimental data will be used for further tests related to sufficiency evaluation of signals received from the builtin sensors under complex loadings.

KEYwORDS. Carbon fiber composite; Embedded defect; Complex stress state; Digital image correlation technique; Infrared thermography; Deformation.

\section{open Access}

Citation: Wildemann, V. V., Tretyakova, T. V., Strungar, E. M., Tretyakov, M. P., Deformation and failure of carbon fiber composite specimens with embedded defects during tension-torsion test, Frattura ed Integrità Strutturale, 46 (2018) 295-305.

Received: 29.07.2018 Accepted: 13.08.2018 Published: 01.10 .2018

Copyright: (C) 2018 This is an open access article under the terms of the CC-BY 4.0, which permits unrestricted use, distribution, and reproduction in any medium, provided the original author and source are credited.

\section{INTRODUCTION}

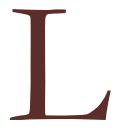

ayer composite materials are widely used to manufacture products for aviation and structural elements using woven prepregs with different technologies. Delamination, damage accumulation in polymer matrix, as well as fiber breaking of fabric (at a later stage) are major types of damages for composites of this class which are prior to the mechanical loss of load-bearing strength and operational performance of structural elements [1,2]. Delamination, inappropriate bonding, inappropriate compacting, cracks, air holes or blow holes [3] have a technology-related origin and refer to different material discontinuities. 
A need to timely reveal operational damages and technological defects requires a prompt control of states of structures and their consequent repairs aimed at service life extension [4-10]. The use of embedded optical fibers with Bragg gratings for the analysis of mechanical behaviour and evaluation of material damage is of interest at this time in the field of monitoring the state of structural elements made from composite materials [11-17]. In order to provide reliability of the monitoring system during operations of real products, it is required to develop the evaluation methods of signal's sufficiency received from fiber-optic sensors under complex loadings [18].

To solve this problem, the methods were developed which aim at mechanical testing of composite specimens with prior introduced technological defects with a joint use of monitoring systems of inhomogeneous deformation fields and temperatures to detect damages with advanced technologies and methods of diagnostics [19-24].

In this paper, we consider the application of the correlation methods of digital images and infrared thermography to analyze the mechanisms of deformation and fracture of specimens with an internal defect under tension with torsion. The obtained experimental data make it possible to estimate the inhomogeneity of the deformation process under complex stress state.

\section{EXPERIMENTAL PROCEDURE}

\section{Material and specimens with embedded defect}

$\mathrm{F}$ lat stripe specimen were prepared from the pre-preg of the serial VKU-39 carbon fiber with prior introduced technological defects for the experimental studies of the mechanisms of deformation and fracture of specimens of layer composite materials with prior introduced technological defects that correspond to possible inappropriate compacting and inappropriate bonding of the material layers at a set restricted domain.

Autoclave moulding from prepregs is used to produce specimens of composite plates, which is the most common technology used in the aviation industry. The production process of specimens with introduced technological defects of the "delamination type" is based on the use of a fluoroplastic film, which is laid according to the scheme of defects arrangement (Fig. 1, a). The work considers two variants of laying the technological defects: 1 is a package of two defects in the form of a square sized $20 \times 20 \mathrm{~mm}^{2}, 2$ is the package of eight defects in the form of a square sized $10 \times 10 \mathrm{~mm}^{2}$ (Tab. 1). The total surface area of the delamination is $S_{d e f}=800 \mathrm{~mm}^{2}$ in both cases. Then the technological package was assembled to carry out the polymerization process in the autoclave complex. To identify the location of the technological defects, nondestructive testing of the workpiece was carried out using ultrasonic method.

\begin{tabular}{|c|c|c|c|}
\hline $\begin{array}{c}\text { Type of laying } \\
\text { defects }\end{array}$ & Number of defects & Defect size, $\mathrm{mm}^{2}$ & $\begin{array}{c}\text { Scheme of laying } \\
\text { defects }\end{array}$ \\
\hline Type 1 & 8 & $10 \times 10$ & $\begin{array}{l}1 \text { and } 2 \text { lay, } \\
2 \text { and } 3 \text { lay, } \\
3 \text { and } 4 \text { lay, } \\
7 \text { and } 8 \text { lay, } \\
8 \text { and } 9 \text { lay, } \\
12 \text { and } 13 \text { lay, } \\
13 \text { and } 14 \text { lay, } \\
14 \text { and } 15 \text { lay }\end{array}$ \\
\hline Type 2 & 4 & $20 \times 20$ & $\begin{array}{l}2 \text { and } 3 \text { lay, } \\
3 \text { and } 4 \text { lay }\end{array}$ \\
\hline
\end{tabular}

Table 1: Type of laying embedded defects in the form of the artificial delamination in composite specimens.

Geometric parameters of the specimens correspond to the parameters of large-sized shell structures, which are used in aircraft engines. The specimens are made using Zund G3-L2500 plotter according to the drawing shown in Fig. 1 (a). An image of the specimen made from a composite material with an internal defect is shown in Fig. 1 (b). It is worth mentioning that the defect is not visible on the specimen's surface.

\section{Testing equipment and testing program}

Mechanical tests on tension with torsion were carried out using the biaxial (tension / torsion) servo-hydraulic test system Instron $8850(100 \mathrm{kN} / 1000 \mathrm{~N} \cdot \mathrm{m})$. During the tests, the dependences between the change of "load-displacement" and "torque-torsion angle" were recorded using the built-in sensors of the test system. 
At the initial stage specimen blades without defects with proportional tension with torsion were tested with the control of position and torsion angle at different ratios of the given displacement and the torsion angle $(k=u / \varphi)$. The testing parameters are given in Tab. 2. The specimens with defects were loaded at the selected ratio of the predetermined displacement to the torsion angle $(k=0.028)$ until ultimate fracture.

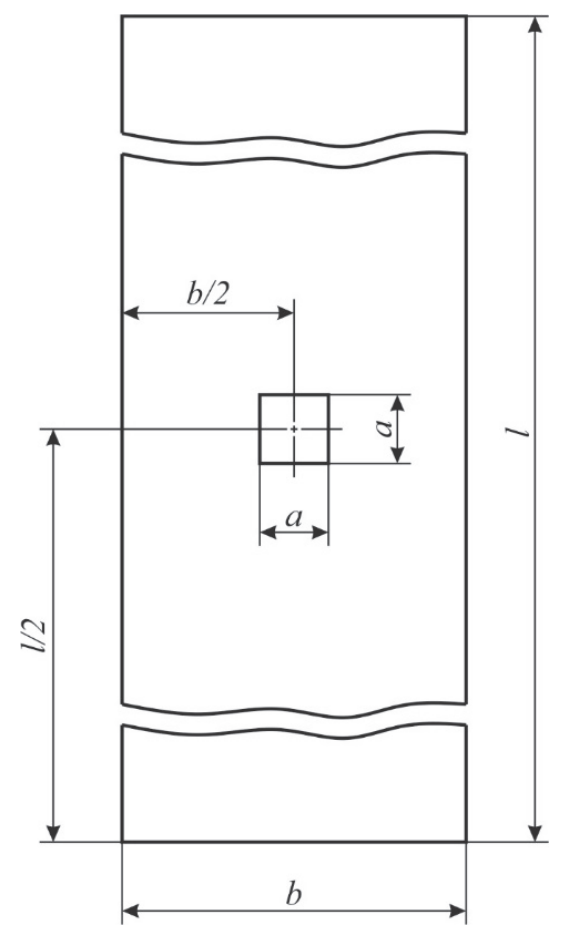

(a)

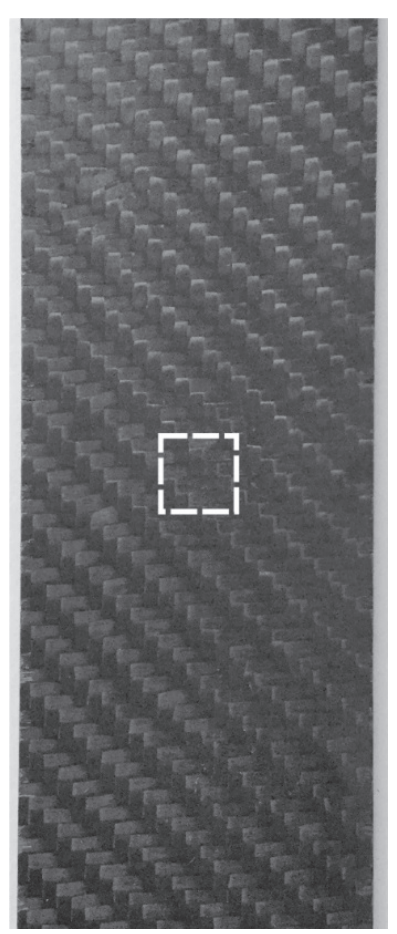

(b)

Figure 1: (a) Sketch and (b) photo of specimen with embedded defect 'delamination'.

\begin{tabular}{cccc}
\hline № & Torsion rate, $\%$ min & $\begin{array}{c}\text { Tension rate, } \\
\mathrm{mm} / \mathrm{min}\end{array}$ & $k=u / \varphi$ \\
1 & 0 & 60 & 0 \\
2 & 5.0 & 60 & 0.083 \\
3 & 5.0 & 90 & 0.056 \\
4 & $\mathbf{2 . 5}$ & $\mathbf{9 0}$ & $\mathbf{0 . 0 2 8}$ \\
\hline
\end{tabular}

Table 2: Test parameters for proportional tension with torsion.

During loading, the displacement and deformation fields were registered on one of the surfaces of the specimens by using the contactless three-dimensional digital optical system Vic-3D. The software of the vision-based system is based on the method of digital images correlation [25]. The shooting is realized by a set of high resolution cameras (Prosilica, $16 \mathrm{Mp}$ ) with a recording frequency of $3.5 \mathrm{~Hz}$.

Post-processing of the obtained images was carried out using the criterion of the normalized sum of squared differences (NSSD); to calculating the fields of longitudinal $\left(\varepsilon_{y y}\right)$, transverse $\left(\varepsilon_{x x}\right)$ and shear deformations $\left(\varepsilon_{x y}\right)$, the finite strain tensor in the Lagrange representation is used. Whereas the axis $O y$ is directed along the specimen (along the axis of tension), the axis $O x$ is perpendicular to the axis of loading in the specimen's plane.

To identify the location and geometric parameters of technological defects of the "delamination type", the method of active infrared thermography was used, while the temperature fields were registered with the infrared thermal imaging system Flir SC7700M. The thermal imager is equipped with a detector of the "cadmium-mercury-tellurium" type, has a resolution of $640 \times 512$ pixels, a recording rate of $115 \mathrm{~Hz}$ (at full resolution) and a sensitivity of $<0.025^{\circ} \mathrm{C}$. 


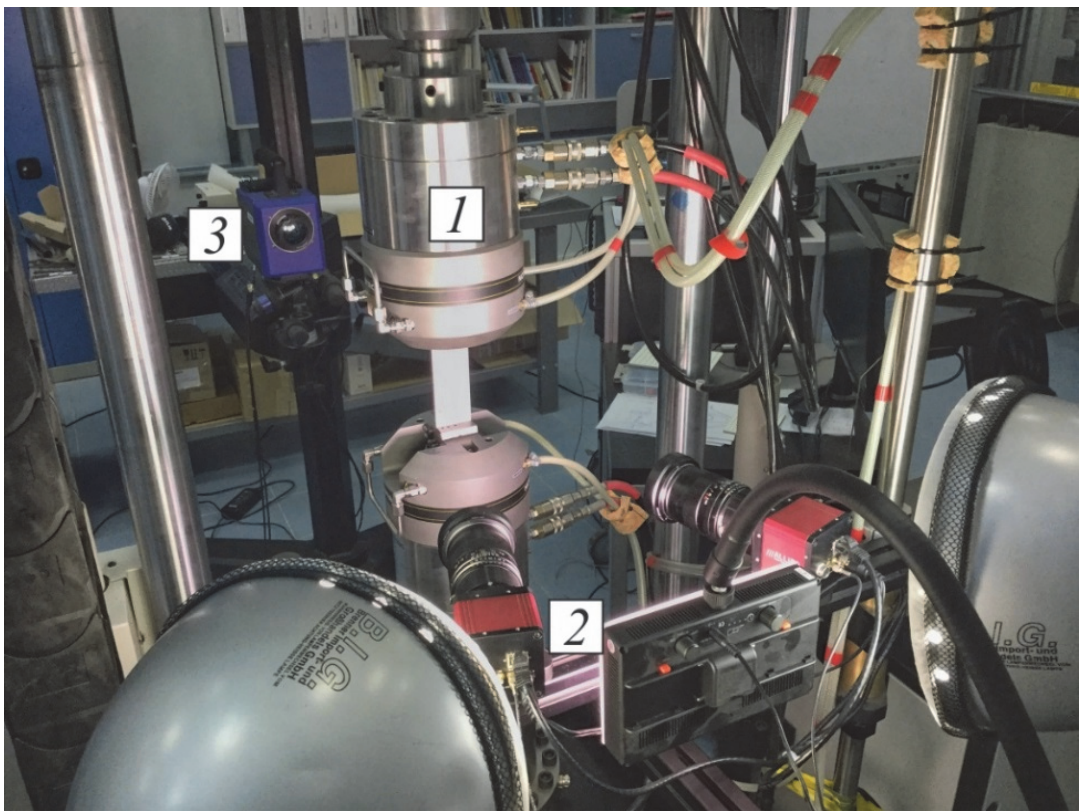

Figure 2: Experimental set-up with the Instron 8850 biaxial servo-hydraulic testing system (1), the DIC measurement system Vic-3D (2) and the infrared system Flir SC7700M (3).

As an example, Fig. 2 shows an image of the relative arrangement of the test and recording equipment. It should be noted that the synchronization of optical recording systems with the test system controller during the test was carried out by means of the Analog-to-Digital Converter unit (NI USB-6251).

\section{MECHANICAL TESTING.}

\section{Procedure of defect identification}

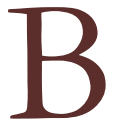

efore carrying out mechanical tests of the specimens with technological defects of the "delamination type", it is necessary to determine the location and geometric parameters of the defects. The method of identifying the technological defects is based on using the method of active infrared thermography [26]. The tested specimens were heated with the incandescent electric lamp with the intensity of $150 \mathrm{~W}$ during 10 seconds at a distance of $0.1 \mathrm{~m}$. During the heating, the temperature fields were recorded with the FLIR SC7700M thermal imaging system.

Fig. 3 shows the analysis results of inhomogeneous temperature fields illustrating internal defects in specimens. The temperature field is given in the values of the temperature change, where the value of $\Delta T$ is obtained by subtracting the first frame from a series of images obtained during the imaging. The use of this method made it possible to visualize the configuration of the internal defect, and also to register and evaluate the defect displacement relative to the center of the working part of the specimen (Fig. 3, b).

\section{Tension with torsion testing of specimen without defects}

Mechanical testing of blade specimens without defects were made under proportional tension with torsion with different ratios of the given displacement and the torsion angle in the range of $k=0 \div 0.083$. The following ratio $k=0.028$ was chosen to carry out further studies of specimens with an internal defect. With this relation, great values of both the tensile force and the torque are achieved.

Fig. 4 shows the curves of the "load-displacement" and "torque-torsion angle" dependences according to the built-in sensors of the test system, obtained with the selected ratio $u / \varphi$. As an example, Fig.4 (b) shows the image of the specimen after testing. It is worth mentioning that the macrofracture of the tested specimens took place in the gripping part under the axial load of $P_{\max }=48.2 \mathrm{kN}$ and torque $M_{\max }=72.2 \mathrm{~nm}$. 


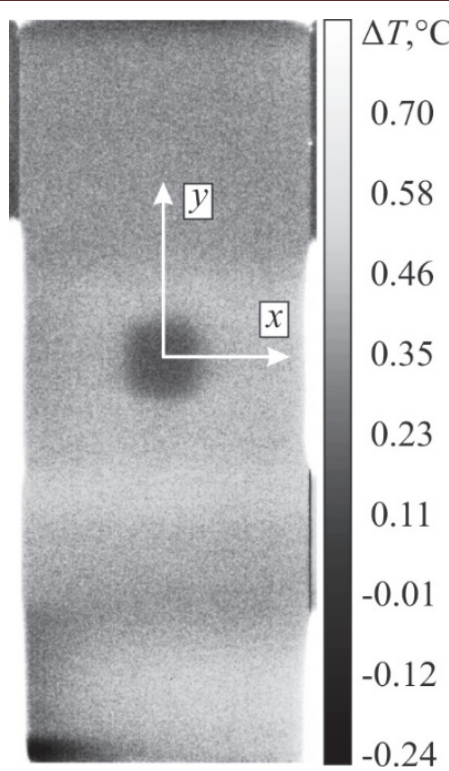

(a)

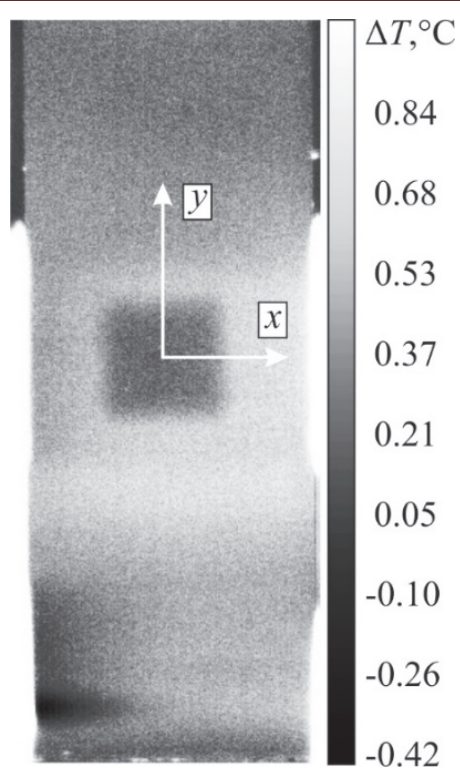

(b)

Figure 3: Temperature fields on specimen surface with different type of laying defects: (a) type 1, (b) type 2.

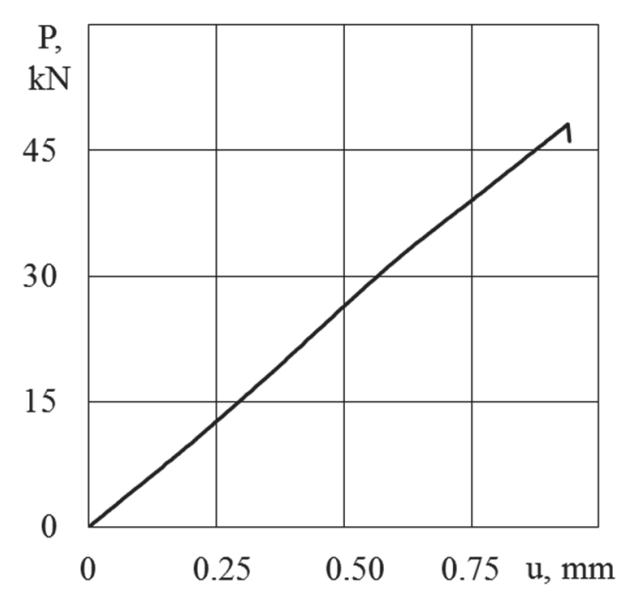

(a)

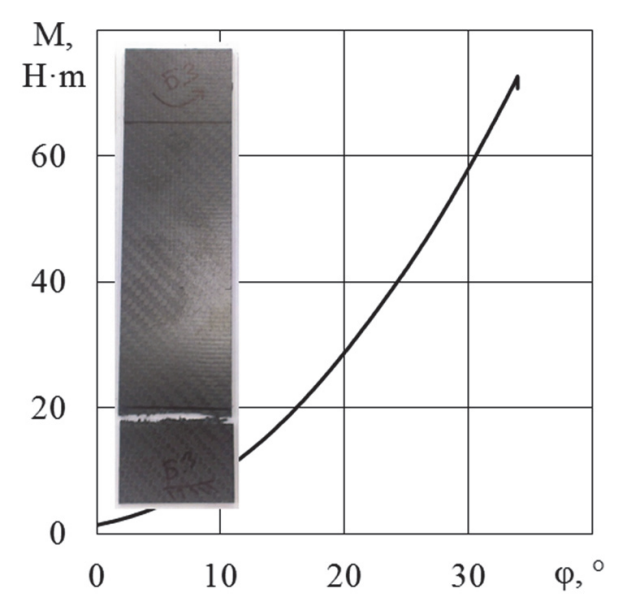

(b)

Figure 4: The ' $P \sim u^{\prime}$ ' (a) and ' $M \sim \varphi$ ' (b) curves obtained in tension-torsion test of specimen without defects $(k=0.028)$.

\section{Tension with torsion testing of specimen with embedded defects}

In order to experimentally study the mechanisms of inelastic deformation and fracture of specimens of carbon fiber with internal defects under complex stress state, mechanical tests are performed with the proportional tension with torsion with the ratio $k=0.028$. To evaluate the development of the internal defect, tests were carried out with three reloadings and repeated loadings. The reloading was performed until the level of the axial load was $P=10 \mathrm{kN}$. In the case of the internal defect formation under loading, a possible change of the images of deformation fields at the time of reloading is assumed. Comparison of the configuration of the longitudinal deformation fields during reloading will allow to estimate the increase in the region of delamination of the composite material.

Fig. 5 shows loading diagrams in the "load-displacement" and "torque-torsion angle" coordinates obtained by the tensiontorsion of specimens with internal defects sized $20 \times 20 \mathrm{~mm}^{2}$ and $10 \times 10 \mathrm{~mm}^{2}$. The diagrams are also built based on the data of the built-in sensor of the test system. 

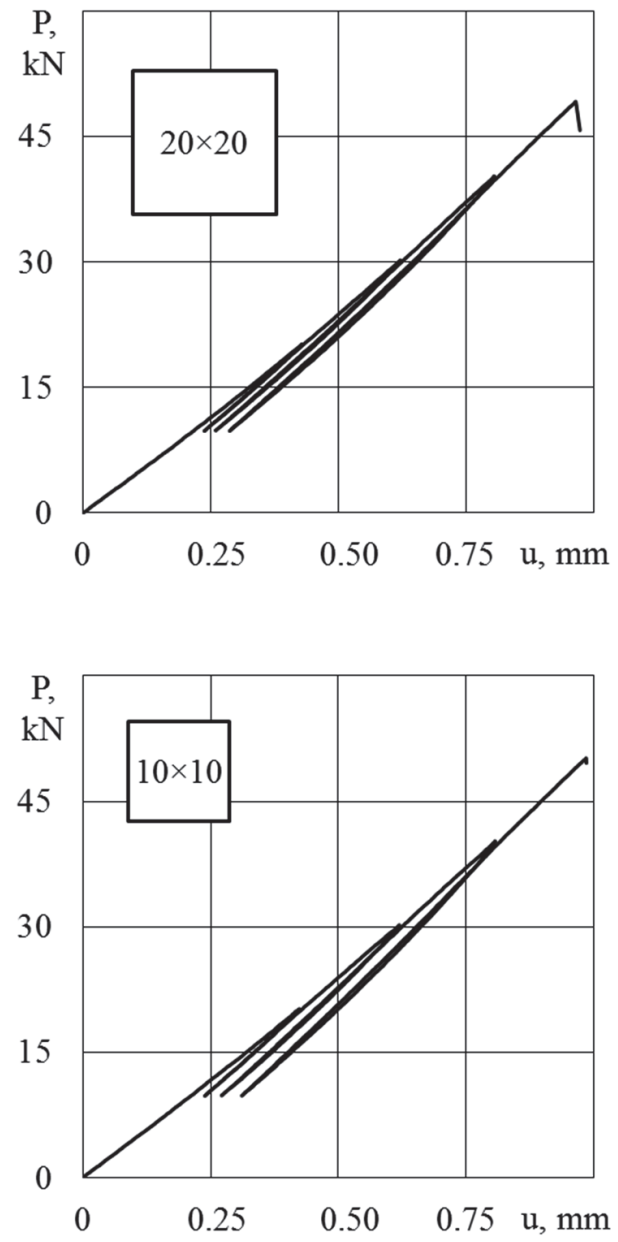

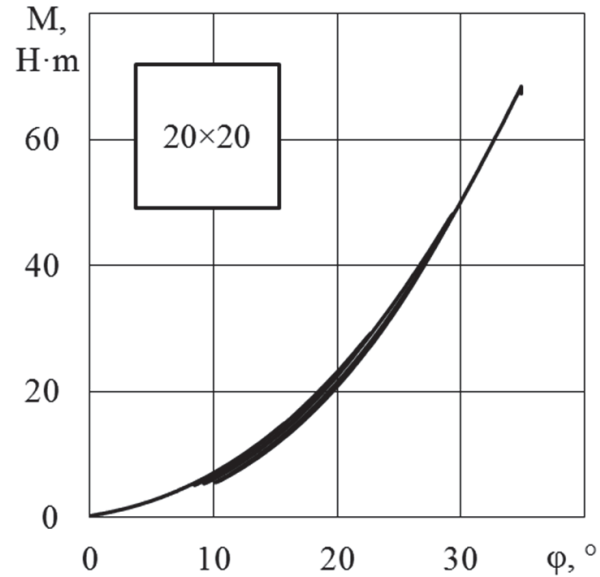

(a)

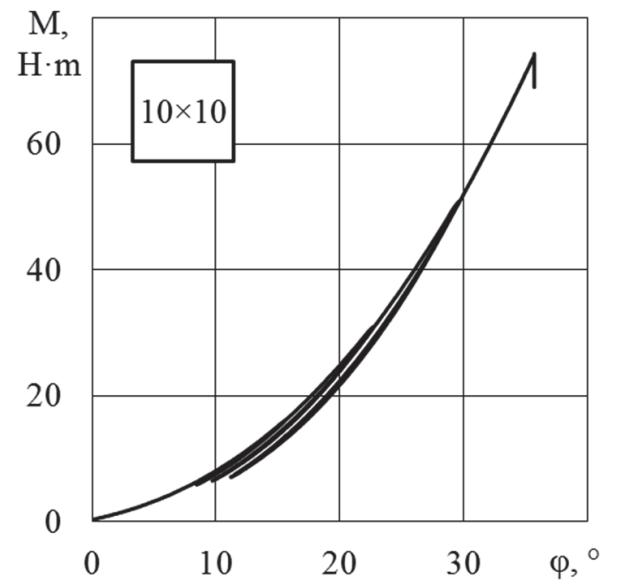

(b)

Figure 5: The ' $P \sim u^{\prime}$ ' and ' $M \sim \varphi$ ' curves obtained in tension-torsion test of specimen with embedded defects $(k=0.028)$ : (a) type 1 , (b) type 2.

It is of interest to analyze the evolution of inhomogeneous longitudinal deformation fields on the surface of the studied specimens under loading. Fig. 6 shows the time dependence of the axial load for a specimen with a defect of $20 \times 20 \mathrm{~mm}^{2}$ (Fig. 7). For the points $t_{0}-t_{4}$ the evolution of the longitudinal deformation fields $\left(\varepsilon_{y y}\right)$ is presented in Fig. 7. The axis $O y$ is directed along the loading axis of the specimen. It is worth mentioning that there is an insignificant increase of thickness in the region of the defect, which is associated with the characteristic property of the "delamination type" defect development on the specimen's surface. This thickening is recorded by the video system and illustrated in Fig. 7 as an image of the distribution of the coordinate $\mathrm{z}$ (the axis $O_{z}$ is perpendicular to the plane of the specimen). Points $t_{1}^{\prime}-t_{3}^{\prime}$ correspond to the specimen's reloading instances at $P=10 \mathrm{kN}$.

In the region of the defect, the presence of inhomogeneity of the longitudinal deformation fields was observed, while in this zone the level of longitudinal deformation is below the average value over the whole specimen. The degree of inhomogeneity increases in the process of loading. To illustrate the observed defect, the dependences of longitudinal deformations were built along the specimen (along the axis $O y$ ) for points $t_{0}-t_{4}$ (Fig.8). The level of the axial load ( $P$ ) in the specified points is equal to $10,20,30,40$ and $50 \mathrm{kN}$ respectively. Vertical dashed lines show the boundaries of the defect. Fig. 9 shows similar dependences of longitudinal deformations, built for points $t_{0}$ and $t_{1}^{\prime}-t_{3}^{\prime}$. It should be noted that the configuration of the curves $\varepsilon_{y y} \sim y$ at the instants of the specimen's reloading at the level of axial load $P=10 \mathrm{kN}$ does not change, which indicates that the internal defect does not develop during the test. 


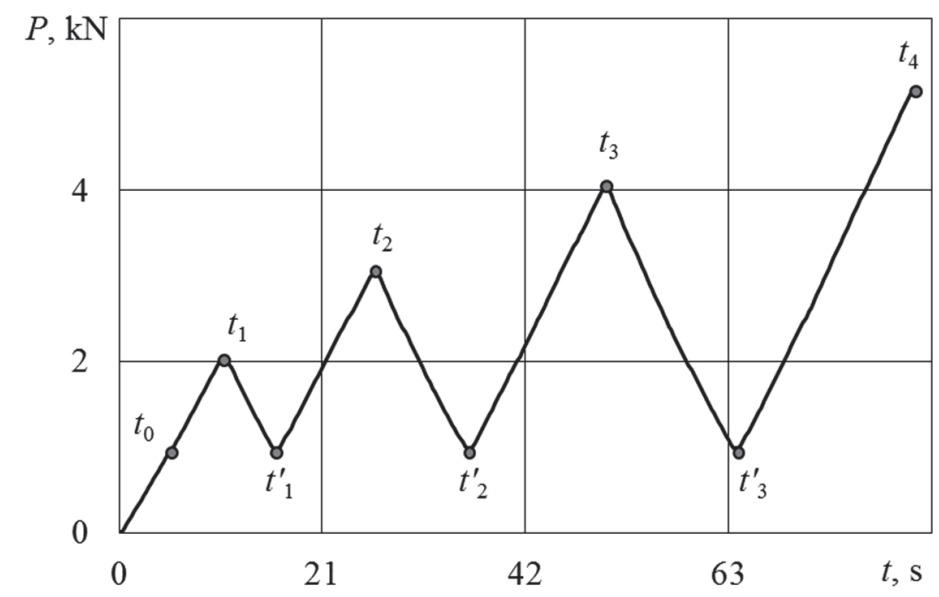

Figure 6: the 'load-time' diagram obtained for specimen with embedded defect of $20 \times 20 \mathrm{~mm}^{2}$ (type 1).
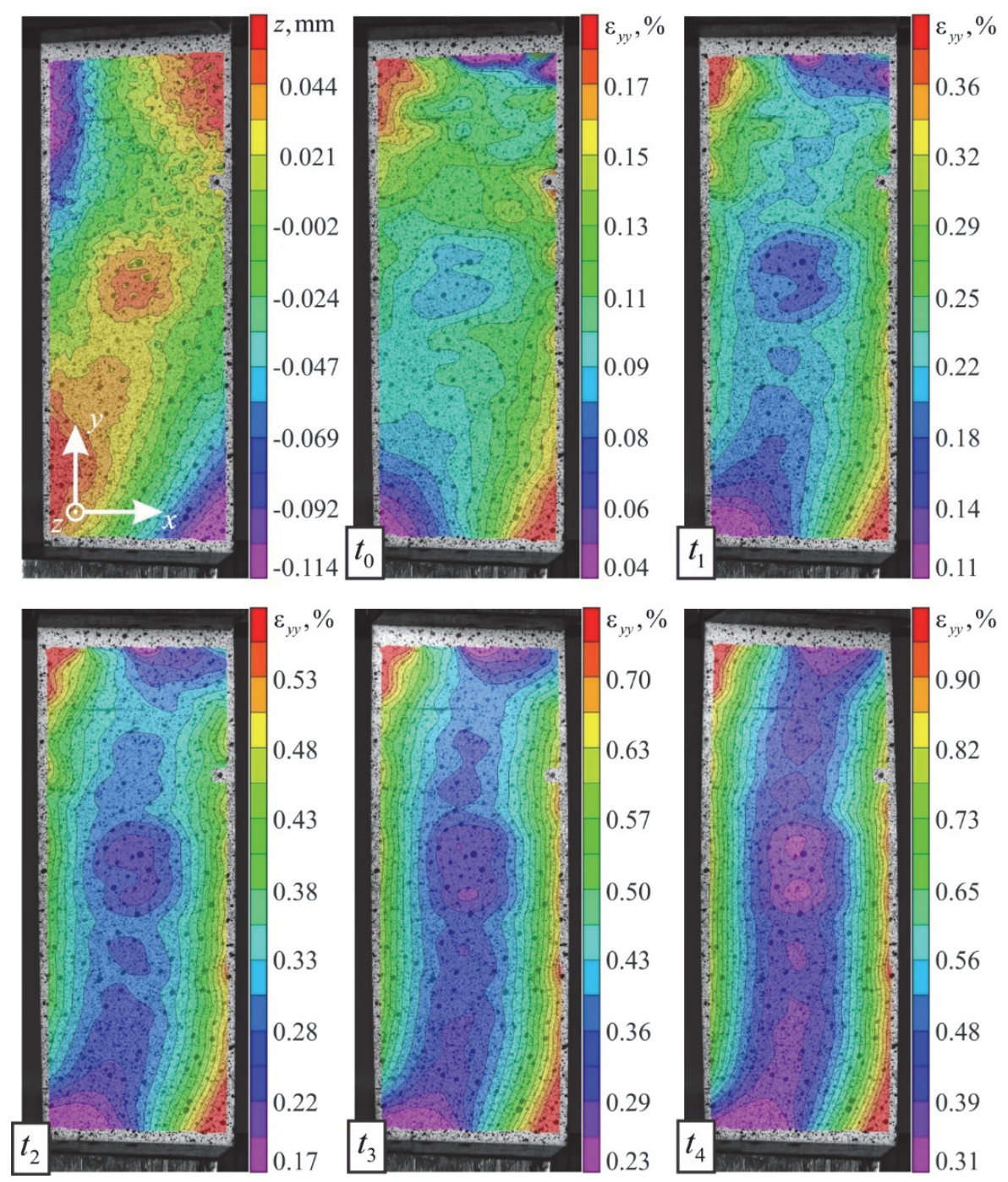

Figure 7: Evolution of the longitudinal strain fields at points $t_{0}-t_{4}$ on the surface of the specimen with embedded defect of $20 \times 20$ $\mathrm{mm}^{2}$ (type 1). 


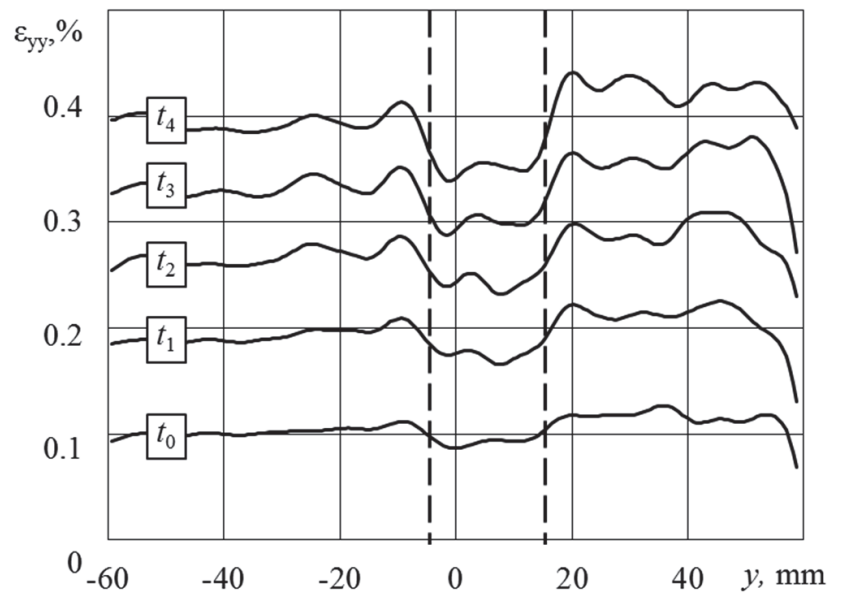

Figure 8: Profiles of the longitudinal strain during uniaxial tension at points $t_{0}-t_{4}$ on the surface of the specimen with embedded defect of $20 \times 20 \mathrm{~mm}^{2}$ (type 1 ).

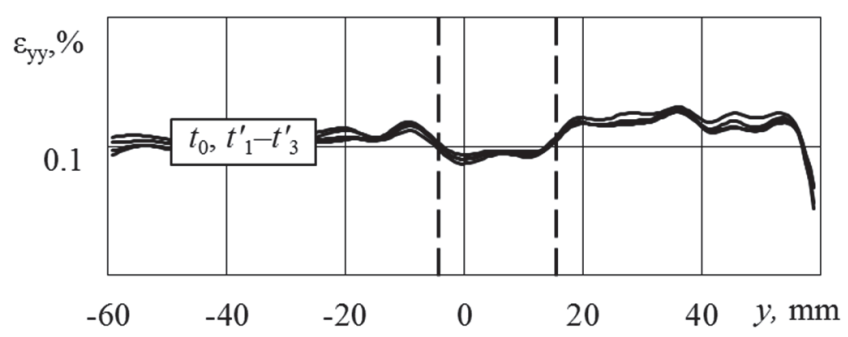

Figure 9: Profiles of the longitudinal strain during uniaxial tension at points $t_{0}, t_{1}^{\prime}-t_{3}^{\prime}$ on the surface of the specimen with embedded defect of $20 \times 20 \mathrm{~mm}^{2}$ (type 1$)$.

A similar analysis of inhomogeneous fields of displacements and deformations was made for the specimen with the internal defect of a smaller size (with the material delamination size of $10 \times 10 \mathrm{~mm}^{2}$ ). Fig. 10 presents the evolution of the longitudinal deformation fields $\left(\varepsilon_{y y}\right)$ and the distribution of $z$ coordinate. The time dependence of the axial load for the specimen with a defect of $20 \times 20 \mathrm{~mm}^{2}$ (Fig. 6) is also characteristic for the specimen with the defect sized $10 \times 10 \mathrm{~mm}^{2}$. Evolution of $\varepsilon_{y y}$ fields is given for similar points $t_{0}-t_{4}$.

For the specimen with the defect of $10 \times 10 \mathrm{~mm}^{2}$, the thickening of the specimen in the region of the internal defect is more obvious because of a greater number of delaminations of the composite (Fig. 10). For this configuration of the defect, a smaller degree of inhomogeneity of the longitudinal deformation fields was noted and, as a consequence, a minor effect of the internal defect on the process of deformation and macrofracture of the specimen.

In contrast to the specimen with an internal defect of a larger size $\left(20 \times 20 \mathrm{~mm}^{2}\right)$, the localization of longitudinal deformations with a value above the average over the whole specimen was seen in the "delamination" region (Fig. 11). The degree of inhomogeneity of inelastic deformation of the material increases in the process of loading. The analysis of curves in the reloading points $\left(t_{0}\right.$ and $\left.t_{1}^{\prime}-t_{3}^{\prime}\right)$ also revealed no increase of the material delamination in the region of inner defect.

\section{CONCLUSIONS}

hus, as a result of the mechanical tests under tension and joint tension with torsion, the experimental data on the patterns of inelastic deformation and fracture of the specimens of the layer composite material with prior introduced technological defects that correspond to possible inappropriate compacting and bonding of material layers at a given restricted domain were obtained. 

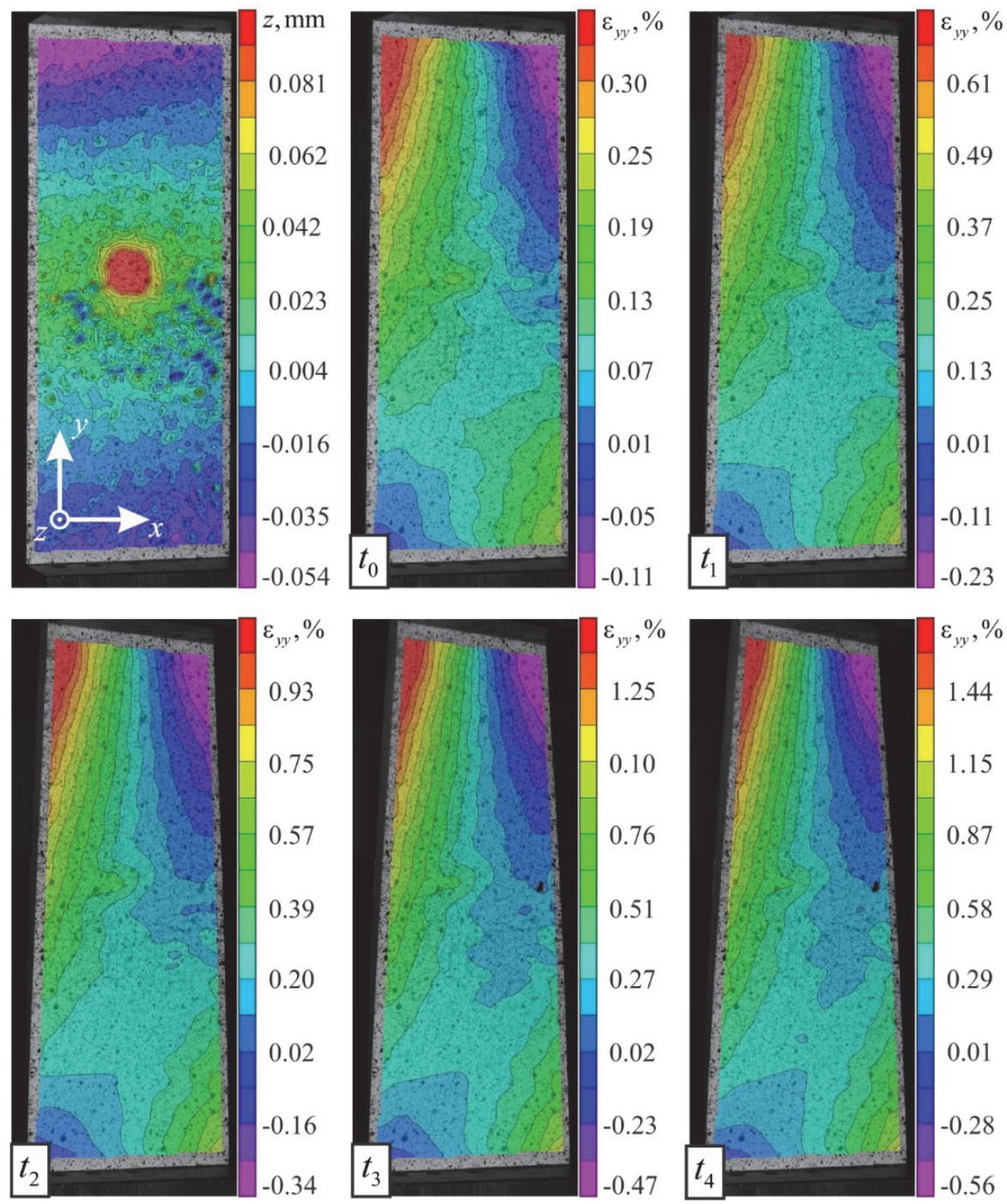

Figure 10: Evolution of the longitudinal strain fields at points $t_{0}-t_{4}$ on the surface of the specimen with embedded defect of $10 \times 10$ $\mathrm{mm}^{2}$ (type 2).

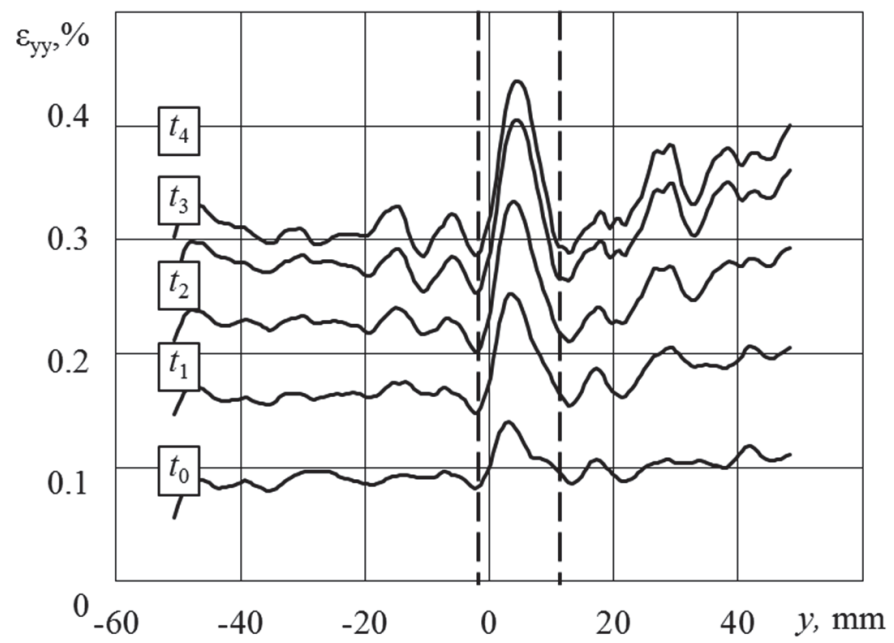

Figure 11: Profiles of the longitudinal strain during uniaxial tension at points $t_{0}-t_{4}$ on the surface of the specimen with embedded defect of $10 \times 10 \mathrm{~mm}^{2}$ (type 2 ). 
The evaluation was made regarding the applicability of the method of digital image correlation (DIC) based on the use of the contactless three-dimensional digital optical system Vic-3D to study the mechanisms of the development of internal defects in composites under complex stressed state. Data are obtained on the evolution of the displacement fields and deformation components in the loading process, which characterize the effect of internal defects on the behaviour of layered carbon plastic and deformation mechanisms. The work uses the method of active infrared thermography to identify internal defects in the specimens and determine the actual configuration of delamination.

Based on the results of the tests, it was concluded that the use of modern diagnostic tools during studies makes it possible to detect internal defects and analyze the mechanisms of deformation and fracture in specimens of composite materials. It is important to note the prospects of a joint use of optical systems aimed at recording deformation fields and temperatures during the control and diagnostics of seminatural and full-sized elements of composite structures.

Based of the obtained experimental data, it can be concluded that for an effective evaluation of a defect development in a composite specimen, it is reasonable to take into account the results not only of tension under static load but also under compression, as well as cyclic effect.

\section{ACKNOWLEDGMENTS}

7 he study was carried out in Perm National Research Polytechnic University and funded by the Russian Science Foundation according to the research project №15-19-00243.

\section{REFERENCES}

[1] Senthil, K., Arockiarajan, A., Palaninathan, R., Santhosh, B. and Usha, K.M. (2013). Defects in composite structures: Its effects and prediction methods - A comprehensive review, Composite Structures, 106, pp. 139-149.

DOI: 10.1016/j.compstruct.2013.06.008.

[2] Lobanov, D.S., Wildemann, V.E., Spaskova, E. M. and Chikhachev, A.I. (2015). Experimental investigation of the defects influence on the composites sandwich panels strength with use digital image correlation and infrared thermography methods. PNRPU Mechanics Bulletin. 4, pp. 159-170. DOI: 10.15593/perm.mech/2015.4.10.

[3] Panin, S.V., Burkov, M.V., Byakov, A.V. and Lyubutin, P.S. (2012). A combined method for studying the deformation and fracture of samples from a carbon-carbon composite material from acoustic emission data, the correlation of digital images and tensometry, Siberian Journal of Science, Tomsk Polytechnic University (TPU), 4 (5), pp. 129-138 (in Russian).

[4] Panding, W., Hongshuai, L., Xiaolei, Z., Haosen, C., Changxian, W. and Daining, F. (2018). Effect of manufacturing defect on mechanical performance of plain weave carbon/epoxy composite based on 3D geometrical reconstruction, Composite Structures, 199, pp. 38-52. DOI: 10.1016/j.compstruct.2018.05.066.

[5] Xie, N., Smith, R. A., Mukhopadhyay, S. and Hallett, S. R. (2018). A numerical study on the influence of composite wrinkle defect geometry on compressive strength, Materials and Design, 140, pp. 7-20. DOI: 10.1016/j.matdes.2017.11.034.

[6] Lobanov, D.S., Wildemann, V.E., Spaskova, E. M. and Chikhachev, A.I. (2015). Experimental investigation of the defects influence on the composites sandwich panels strength with use digital image correlation and infrared thermography methods, PNRPU Mechanics Bulletin, 4, pp. 159-170. DOI: 10.15593/perm.mech/2015.4.10.

[7] Serovaev, G.S. and Matveenko, V.P. (2016). Numerical study of the response of dynamic parameters to defects in composite structures, Frattura ed Integrità Strutturale, 10(38), pp. 392-398. DOI: 10.3221/IGF-ESIS.38.48.

[8] Tashkinov, M.A. (2017). Modelling of fracture processes in laminate composite plates with embedded delamination, Frattura ed Integrità Strutturale, 11 (39), pp. 248-262. DOI: 10.3221/IGF-ESIS.39.23.

[9] Tretyakov, M.P., Tretyakova, T.V. and Wildemann, V.E. (2018). Regularities of mechanical behavior of steel 40Cr during the postcritical deformation of specimens in condition of necking effect at tension, Frattura ed Integrita Strutturale, 12(43), pp. 146-154. DOI: 10.3221/IGF-ESIS.43.11.

[10] Tretyakova, T.V. and Spaskova, E.M. (2013). Experimental study of limit stress-strain state quasi-brittle material using correlation techniques digital images, PNRPU Mechanics Bulletin, 2, pp. 186-201. 
[11] Tserpes, K.I., Karachalios, V., Giannopoulos, I., Prentzias, V. and Ruzek, R. (2014). Strain and damage monitoring in CFRP fuselage panels using fiber Bragg grating sensors, Part I: Design, manufacturing and impact testing, Composite Structures, 107, pp. 726-736. DOI: 10.1016/j.compstruct.2013.09.053.

[12] Pratik, S., Jin-Hyuk, K., Yurim, P. and Chun-Gon, K. (2015). Impact Localization on Composite Wing using 1D Array FBG Sensor and RMS, Correlation Based Reference Database Algorithm, Composite Structures, 125, pp. 159-169. DOI: 10.1016/j.compstruct.2015.01.029.

[13] Sang-Woo, K., Eun-Ho, K., Min-Soo, J. and In, L., (2015). Damage evaluation and strain monitoring for composite cylinders using tin-coated FBG sensors under low-velocity impacts, Composites Part B: Engineering, 74, pp. 13-22. DOI: $10.1016 /$ j.compositesb.2015.01.004.

[14] Anoshkin, A. N., Voronkov, A. A., Kosheleva, N. A., Matveenko, V. P., Serovaev, G. S., Spaskova, E. M., Shardakov, I. N. and Shipunov, G. S. (2017). Measurement of Inhomogeneous Strain Fields by Fiber Optic Sensors Embedded in a Polymer Composite Material, Mechanics of Solids, 51(5), pp. 542-549. DOI: 10.3103/S0025654416050058.

[15] Lobanov, D.S., Shipunov, G.S. and Voronkov, A.A. (2017). Evaluation of the operability and expediency of using fiberoptical sensors embedded in a composite material at elevated temperatures, Bulletin of the Perm National Research Polytechnic University. Aerospace engineering, 50, pp. 36-45. DOI: 10.15593/2224-9982/2017.50.04 (in Russian).

[16] Kosheleva, N.A., Shipunov, G.S., Voronkov, A.A., Merkusheva, N.P. and Tihonova, A.A. (2017). Determination of the stress-strain state fields of samples from a polymeric composite material using fiber optic sensors, Bulletin of the Perm National Research Polytechnic University. Aerospace engineering, 50, pp. 26-35.

DOI: 10.15593/2224-9982/2017.50.03 (in Russian).

[17] Korepanov, V. V., Serovaev, G. S. and Yurlova, N. A. (2016). Numerical Modelling of Layered Composite Materials With Embedded Optical Fiber Sensors, Solid State Phenomena, 243, pp. 83-88.

DOI: $10.4028 /$ www.scientific.net/SSP.243.83.

[18] Wildemann, V.E., Strungar, E.M., Lobanov, D.S. and Voronkov, A.A. (2018). Evaluation of the performance of fiberoptical sensors embedded in a composite material using data from a digital optical video system for analyzing deformations, Defectoskopiya. 1, pp. 65-71 (in Russian).

[19] Pastuszak, P. D. (2016). Characterization of defects in curved composite structures using active infrared thermography, Procedia Engineering, 157, pp. 325 - 332. DOI: 10.1016/j.proeng.2016.08.373.

[20] Elhajjar, R. F. and Shams, S. S. (2016). A new method for limit point determination in composite materials containing defects using image correlation, Composites Science and Technology, 122, pp. 140-148. DOI: $10.1016 /$ j.compscitech.2015.11.026.

[21] Johanson, K., Harper, L. T., Johnson, M. S. and Warrior, N. A. (2015). Heterogeneity of discontinuous carbon fibre composites: damage initiation captured by digital image correlation, Composites Part A: Applied Science Manufacturing, 68, pp. 304-312. DOI: 10.1016/j.compositesa.2014.10.014.

[22] Wildemann, V. E., Spaskova, E. V. and Shilova, A. I. (2016). Research of the damage and failure processes of composite materials based on acoustic emission monitoring and method of digital image correlation, Solid State Phenomena, 243, pp. 163-170. DOI: 10.4028/ww.scientific.net/SSP.243.163.

[23] Tetyakova, T.V. and Wildemann, V.E. (2017). Influence the loading conditions and the stress concentrators on the spatial-time inhomogeneity due to the yield delay and the jerky flow: study by using the digital image correlation and the infrared analysis, Frattura ed Integrità Strutturale, 42, pp. 303-314. DOI: 10.3221/IGF-ESIS.42.32.

[24] Fedorova, A.Y., Bannikov, M.V., Plekhov, O.A. and Plekhova, E.V. (2012). Infrared thermography study of the fatigue crack propagation, Frattura ed Integrita Strutturale, 21, pp. 46-53. DOI: 10.3221/IGF-ESIS.21.06.

[25] Sutton, M.A., Orteu, J.-J. and Schreier, H. (2009). Image Correlation for Shape, Motion and Deformation Measurements, University of South Carolina, Columbia, SC, USA. DOI: 10.1007/978-0-387-78747-3.

[26] Chulkov, A.O. and Vavilov, V.P. (2016). Hardware and Software for Thermal Nondestructive Testing of Metallic and Composite Materials, Journal of Physics: Conference Series, 671(1), 012011. DOI: 10.1088/1742-6596/671/1/012011. 